\title{
Cyclosomatostatin-induced catalepsy in the aged rat: a response to levodopa, diphenhydramine and nicotine
}

\author{
Ilya D. Ionov ${ }^{1, *}$, Irina I. Pushinskaya ${ }^{2}$ and Nicholas P. Gorev ${ }^{2}$ \\ ${ }^{1}$ Centre on Theoretical Problems in Physical and Chemical Pharmacology, Russian Academy of Sciences, \\ Leninsky Prospect 123-4-63, Moscow 117513; ${ }^{2}$ Timpharm LTD, Moscow, Russia.
}

\begin{abstract}
A decrease in somatostatin level is observed in parkinsonian brain. We recently reported that rats given an intracerebroventricular injection of a somatostatin antagonist, cyclosomatostatin, fall into catalepsy; the effect was observed in aged but not young animals. To evaluate the predictive validity of the cyclosomatostatin-induced catalepsy as a model of extrapyramidal disorders, the sensitivity of this catalepsy to clinically effective antiparkinsonian agents was determined. We examined the effects of levodopa and histamine antagonists; also, given an inverse association between Parkinson's disease and tobacco smoking, nicotine was tested. The experiments were conducted using 27-28month-old male Wistar rats. Catalepsy was measured using the bar test. Cyclosomatostatin-induced catalepsy was strongly antagonized by levodopa, which indicates a role for central dopaminergic deficiency in this model. Similarly, histamine $\mathrm{H}_{1}$ receptor antagonist, diphenhydramine, exhibited anticataleptic activity; in contrast, antagonists at $\mathrm{H}_{2}$ and $\mathrm{H}_{3}$-receptors were without effect. Cataleptic response was inhibited by nicotine; the nicotine sensitivity distinguishes this catalepsy from other models, in particular, from haloperidol-induced catalepsy. Diphenhydramine and nicotine alone only partly suppressed catalepsy; however, coadministration of these drugs almost totally reversed the cataleptogenic effect of cyclosomatostatin.
\end{abstract}

\footnotetext{
*Corresponding author: newrology@yandex.ru
}

Thus, a similarity between the cyclosomatostatininduced catalepsy and Parkinson's disease with regard to the sensitivity to anti-parkinsonian agents was found. This supports the validity of the model as well as the role of somatostatinergic deficiency in the mechanism of parkinsonian symptoms. Coadministration of diphenhydramine and nicotine appears to be a promising treatment for extrapyramidal disorders in Parkinson's disease.

KEYWORDS: aging, somatostatin, histamine, nicotine, catalepsy, Parkinson's disease.

\section{INTRODUCTION}

Parkinson's disease is characterized by progressive damage to dopaminergic neurons in the substantia nigra; bradykinesia and other extrapyramidal signs are the major features of the disease [1-3]. Age is the largest risk factor for the development of parkinsonism [4]; alternatively, tobacco smoking decreases the incidence of the illness [5]. The fall in dopaminergic activity detected in parkinsonian brain has encouraged attempts to pharmacologically replace the missing neurotransmitter. Treatment with 3,4-dihydroxy-L-phenylalanine (levodopa), a precursor of dopamine, has led to marked relief of motor symptoms [6] supporting the causative role of dopaminergic deficiency in parkinsonian pathology. In the past decades, various therapeutic strategies were proposed; however, none of them could stop or slow disease progression.

A number of animal models are currently in use to identify new potential anti-parkinsonian therapies. 
Neurotoxic models use toxins causing reversible or irreversible injury to dopaminergic neurons; genetic models are based on genetic mutations that either selectively disrupt nigral neurons or are similar to mutations found in familial parkinsonism [7]. Meanwhile, there is presently no model that would use factors characteristic of idiopathic Parkinson's disease (iPD). As it seems, such models may be of special significance in the search for novel anti-parkinsonian agents.

One of the iPD-associated brain abnormalities is a fall in somatostatin levels (for refs., see $[8,9]$ ). These changes may be of pathogenic importance as somatostatin can stimulate dopaminergic neurotransmission [10-12].

We recently simulated a decrease in brain somatostatin activity in Wistar rats $[8,9,13]$ using intracerebral injections of cyclosomatostatin (cS), an antagonist of somatostatin receptors [14]. It has been found that $\mathrm{cS}$ induces cataleptic response. Catalepsy, an abnormal behavior that resembles bradykinesia and postural rigidity in iPD, is often linked to an inhibition of central dopaminergic activity $[15,16]$ and thereby is used as a model of extrapyramidal dysfunctions. In our experiments, the cS effect was observed in aged but not young rats [8]. Thus, cS-induced catalepsy displayed an age-dependence similar to that of iPD. Apparently, this property of the model supports its validity.

The present work is aimed to study cS-induced catalepsy with reference to its sensitivity to some pharmacological challenges. First, levodopa should be examined; apparently, the responsiveness of this catalepsy to clinically effective agents would support the model's predictive validity [17]. Since existence of a levodopa-unresponsive type of catalepsy has been described [18], the determination of levodopa sensitivity seems to be necessary for the evaluation of any new model of iPD.

Second, the sensitivity of cS-induced catalepsy to histamine receptor antagonists should be examined because histamine is believed to regulate brain dopamine activity. In mammals, the striatum receives a major input from the hypothalamic tuberomammillary nucleus, the major source of brain histamine [19]. In rats and mice, the activity of histidine decarboxylase, the enzyme which forms histamine, is strongly increased in the striatum compared with other brain areas [20]; it seems likely that the regulation of dopaminergic neurotransmission is a special physiological function of brain histamine. The significance of the histaminergic projection for the striatum is supported by findings of changed striatal dopamine metabolism after a lesion to the tuberomammillary nucleus [21]. In mice, a precursor of histamine, histidine, suppressed a dopamine-dependent behavior, methamphetamineinduced locomotor hyperactivity [22]. In rats, histidine potentiated the cataleptogenic effect of a dopamine receptor antagonist haloperidol [23]. In direct experiments, exogenous histamine produced selective degeneration of dopaminergic neurons in rat substantia nigra [24]; in essence, histamine is the only brain factor that is found to induce the main histopathological feature of iPD. Besides, in mice, histamine can exert catalepsy that is antagonized by levodopa [25-27]. Alternatively, histamine $\mathrm{H}_{1}$ receptor antagonists can elevate dopamine levels in rat neostriatum and nucleus accumbens [28]; these drugs also attenuate cataleptic response induced by haloperidol [23, 29] and a few other cataleptogens [29]. In view of these data, histamine receptor blockers seem to be promising therapeutics for iPD, at least as a part of treatment strategy. With this in mind, we examined histamine antagonists in the cS-induced catalepsy model.

Finally, the sensitivity to nicotine may be indicative of the model's validity. Given a lower risk of iPD in tobacco smokers [5], nicotine may be expected to bring about an anti-parkinsonian effect. The influence of nicotine on dopaminergic system has been previously examined in many studies; however, inconsistent results were obtained. Nicotine in vitro protected dopaminergic neurons against a range of toxic insults (e.g., review [30]); by contrast, in vivo the drug can increase the vulnerability of the nigral neurons to a neurotoxin [31]. In rodents, nicotine stimulated dopamine release from striatal cells in vitro $[32,33]$ and in vivo [34]. However, acute administration of nicotine potentiated rather than inhibited catalepsy induced in rats by haloperidol [35-37] and a few other cataleptogenic drugs $[38,39]$. To date, the influence of nicotine on somatostatin-mediated brain mechanisms has not been studied. Given this, we assessed the influence of nicotine on cS-induced catalepsy. 
Another aim of this study is to evaluate the sensitivity of cS-induced catalepsy to combined treatment with an antagonist of histamine $\mathrm{H}_{1}$ receptors (diphenhydramine) and nicotine.

\section{MATERIALS AND METHODS}

\section{Animals}

The experiments were conducted using 27-28month-old male Wistar rats. The average life span of these rats is approximately 25 months [40]; given this, the animals in our study can be deemed old.

Rats were housed four per cage in a well-ventilated colony room having a 12-hour light/dark cycle (lights on at 7:00 AM) and temperature of $22{ }^{\circ} \mathrm{C}$. The animals received standard laboratory rat chow and tap water ad libitum. The animals were adapted to these conditions for a minimum of two weeks before the experiments. For carrying out the experiments, animals were divided randomly into groups of eight each.

\section{Drugs and doses}

Cyclo(7-aminoheptanoyl-Phe-D-Trp-Lys-Thr[Bzl]) (cS), diphenhydramine hydrochloride (DPH), ranitidine hydrochloride (ranitidine), thioperamide maleate salt (thioperamide), levodopa (L-DP), carbidopa, (-)-nicotine hydrogen tartrate salt (NCT), $( \pm)$-ketamine hydrochloride (ketamine), and xylazine hydrochloride (xylazine) were obtained from Sigma-Aldrich (St. Louis, MO, USA). Gentamicin sulfate (Krka, Slovenia) and Polysporin Triple antibiotic ointment (Johnson \& Johnson Inc.) were used as well.

$\mathrm{cS}(0.5,2.0$, and $8.0 \mu \mathrm{g})$ and DPH $(5.0,10.0$, and $20.0 \mu \mathrm{g}$ ) were administered intracerebroventricularly (i.c.v.), and $\mathrm{NCT}(0.2,0.4$, and $1.0 \mathrm{mg} / \mathrm{kg})$ was given subcutaneously. L-DP $(50,100$, and $200 \mathrm{mg} / \mathrm{kg}$ ) was used in combination with carbidopa, an inhibitor of the peripheral conversion of L-DP to dopamine; L-DP and carbidopa (dose ratio 10:1) were administered orally using a gastric tube.

Sterile physiological saline $(0.9 \% \mathrm{NaCl}$ in apyrogenic water) was used as a vehicle for L-DP, carbidopa, and NCT. Other drugs were dissolved in sterile artificial cerebrospinal fluid (aCSF) [41].

The choice of the doses was based on the results of previous studies [8, 42, 43]. Ranitidine and thioperamide were injected i.c.v. at doses of 12.3 and $11.5 \mu \mathrm{g}$, respectively; these doses are equimolar with $10 \mu \mathrm{g}$ of DPH.

All doses represent the free-base equivalent of the salt form. The tested drugs were administered 15 min prior to the injection of $\mathrm{cS}$.

\section{Implantation of cannula}

The surgical operations were done under aseptic conditions. Additionally, before surgery each rat was injected with gentamicin sulfate, $5 \mathrm{mg} / \mathrm{kg}$ intramuscularly. The animal was anaesthetized with intraperitoneal administration of ketamine and xylazine ( 80 and $8 \mathrm{mg} / \mathrm{kg}$, respectively) and placed in a Kopf stereotaxic apparatus (David Kopf Instruments, Tujunga, CA, USA). For intracerebral administration, a 26-gauge stainless steel guide cannula (Plastics One Inc., Roanoke, VA, USA) was stereotaxically implanted into the right lateral ventricle using the following stereotaxic coordinates: $\mathrm{ML}=-1.6 \mathrm{~mm}, \mathrm{DV}=-3.6 \mathrm{~mm}$, and $\mathrm{AP}=-0.8 \mathrm{~mm}$ from bregma [44]. The guide cannula was secured with screws and cranioplastic cement (Dentsply International, York, PA, USA). The cannula was filled with aCSF before implantation. Leakage of fluid from the cannula during implantation was considered as evidence of proper cannula placement [45]. Additionally, the location of the cannula track was verified during sectioning. Animals showing cannula misplacement were excluded from the study.

After placement, the guide cannula was sealed with a sterile dummy cannula (obturator, Plastics One Inc., Roanoke, VA, USA). The incision area was treated topically with Polysporin Triple antibiotic ointment. The animals were allowed to recover for 10 days during which they were caged individually.

\section{Intracerebral injection procedure}

Microinjection of $\mathrm{cS}$ solution or vehicle into the lateral ventricle was performed as described in $[44,46]$. Briefly, a needle connected by polyethylene tubing to a $10 \mu \mathrm{l}$ syringe was used. After removal of the obturator, the needle was protruded $1 \mathrm{~mm}$ beyond the cannula tip and the solution $(10 \mu \mathrm{l})$ was injected over 30 seconds. After the injection, the needle remained in place for $30 \mathrm{~s}$ before withdrawal to prevent injection fluid backflow through the cannula. 


\section{Catalepsy assessment}

Catalepsy in rodents is a state of temporal immobility characterized by failure to correct an externally imposed unusual posture [47, 48]. Bar test was used as a method for the quantitative evaluation of catalepsy. Each rat was placed with its fore limbs on a wooden bar $(9.0 \mathrm{~cm}$ above the table surface, diameter of $1.5 \mathrm{~cm}$ ). The animal's hind paws rested on the table surface. The length of time (s) until the animal placed both paws on the table surface, or moved its head in an exploratory manner, or began to climb on the bar $[49,50]$ was measured; this time is herein termed as duration of immobility. In the first two days the rat was placed on the bar daily to adapt to it [48]. On the third day, the animal was injected with drug(s) or vehicle, and experimental session was performed. To complete one test, the animal was placed on the bar three times and the mean of these three periods of motionlessness was accepted to be the outcome of this test [49]. The time measurements were performed by an experimenter blind to group status. During each session, these measurements were performed $60,120,180$ and $240 \mathrm{~min}$ after administration of the tested solutions with the animals being kept in their home cages between tests. Tactile stimulation of the animals (handling) was minimized for a minimum of eighteen hours before the start of the experiments.

Catalepsy was defined as a significant $(p<0.05)$ increase in the duration of immobility compared to that of the vehicle-treated group.

\section{Outline of the experiments}

Six separate experiments were conducted. Experiment I was carried out to select the dose of $\mathrm{cS}$ for further study. In experiment II, the ability of L-DP (in combination with carbidopa) to influence cS-induced catalepsy was assessed. In experiment III, the sensitivity of the above cataleptic model to $\mathrm{DPH}$, an antagonist at $\mathrm{H}_{1}$-receptor, was examined; dose-response relationship was determined for selection of the lowest effective dose that was used in further studies. In experiment IV, anticataleptic activity of DPH was compared with that of ranitidine and thioperamide, selective antagonists at $\mathrm{H}_{2}$ and $\mathrm{H}_{3}$-receptors. The antagonists were injected i.c.v. at equimolar doses. The goal of experiment $\mathrm{V}$ was to evaluate the sensitivity of
cS-induced catalepsy to NCT. In experiment VI, the anti-cataleptic activity of DPH-NCT combination was evaluated. Two control groups were used in each experiment: unoperated animals and those treated with $\mathrm{cS}$ alone.

\section{Statistical analysis}

Data are expressed as means \pm SEM. The ShapiroWilk W test was used to assess the normality of the data distribution. Since the normality assumptions could not be accepted, comparisons were made with Kruskal-Wallis one-way analysis of variance on ranks followed by Tukey's test for pairwise comparison. Differences with a $p$ value of less than 0.05 were considered statistically significant.

\section{RESULTS}

cS exerted no catalepsy at the doses of 0.5 and $2.0 \mu \mathrm{g}$ (no significant difference was observed between drug- and vehicle-treated groups, $p>0.05$, $\mathrm{n}=8$, experiment I). In contrast, the dose of $8.0 \mu \mathrm{g}$ produced distinct catalepsy (significant difference from vehicle-treated control, $p<0.01$ ); the effect was seen at all time points after injection of cataleptogen (Table 1). These findings basically replicated our previous results (e.g., [8]). The most effective dose, $8.0 \mu \mathrm{g}$, was used in the next stage of the research.

L-DP (in combination with carbidopa) per se failed to induce catalepsy (data not shown) but antagonized cS-induced catalepsy in a dosedependent manner. The dose $50 \mathrm{mg} / \mathrm{kg}$ was ineffective. However, the administration of the drug at larger doses significantly $(p<0.05$ and $<0.01)$ reduced cataleptic response at all time points. The dose of $200 \mathrm{mg} / \mathrm{kg}$ was more effective $(p<0.05)$ than the dose of $100 \mathrm{mg} / \mathrm{kg}$ (Table 2, experiment II).

An antagonist at $\mathrm{H}_{1}$-receptor, DPH, showed no cataleptogenic activity (data not shown) but was found to inhibit cS-induced catalepsy. The dose of $5.0 \mu \mathrm{g}$ was ineffective. The drug at the doses of 10.0 and $20.0 \mu$ g markedly $(p<0.05)$ antagonized cataleptogenic activity of cS (Table 3, experiment III). There was no difference $(p>0.05)$ between the effects induced by DPH at the doses of 10.0 and $20.0 \mu \mathrm{g}$. 
Unlike DPH, antagonists at $\mathrm{H}_{2}$ - and $\mathrm{H}_{3}$-receptors, ranitidine and thioperamide, at equimolar doses failed to affect cS-induced catalepsy (Table 3, experiment IV). Similarly, these drugs did not induce catalepsy per se (data not shown).

Nicotine was found to inhibit cS-induced cataleptic response. The dose of $0.2 \mathrm{mg} / \mathrm{kg}$ was without effect whereas animals treated with NCT at the doses of 0.4 and $1.0 \mathrm{mg} / \mathrm{kg}$ exhibited attenuated $(p<0.05)$ cataleptic response to $\mathrm{cS}$ at all time points (Table 4 , experiment V). The anticataleptic effects exerted by 0.4 and $1.0 \mathrm{mg} / \mathrm{kg}$ of the drug did not differ significantly from each other $(p>0.05)$. NCT on its own at all tested doses did not induce catalepsy (data not shown).

As can be seen in Tables 3 and 4 (Experiments III and V), dose-effect relationship for DPH and NCT is obviously nonlinear and, in the range of large doses, could be characterized as a plateau effect. Given this, it does not seem likely that further increase in the doses of DPH or NCT will lead to more pronounced inhibition of catalepsy. To evaluate the possibility to strengthen the anticataleptic effect, we examined the activity of

Table 1. Cataleptic response to cyclosomatostatin $(\mathrm{cS})$.

\begin{tabular}{|c|c|c|c|c|}
\hline \multirow[t]{2}{*}{ Drug (dose) } & \multicolumn{4}{|c|}{$\begin{array}{l}\text { Duration of immobility (s) } \\
\text { at different time points after } \mathrm{CS} \text { injection }\end{array}$} \\
\hline & $60 \mathrm{~min}$ & $120 \mathrm{~min}$ & $180 \mathrm{~min}$ & $240 \mathrm{~min}$ \\
\hline \multicolumn{5}{|c|}{ Experiment I } \\
\hline Unoperated control & $7.7 \pm 0.85$ & $7.9 \pm 0.96$ & $7.4 \pm 0.73$ & $7.2 \pm 0.85$ \\
\hline Vehicle & $9.2 \pm 1.03$ & $9.0 \pm 0.99$ & $9.1 \pm 0.96$ & $8.7 \pm 0.91$ \\
\hline $\mathrm{cS}(0.5 \mu \mathrm{g})$ & $12.2 \pm 1.42$ & $12.6 \pm 1.53$ & $12.0 \pm 1.44$ & $11.8 \pm 1.46$ \\
\hline $\mathrm{cS}(2.0 \mu \mathrm{g})$ & $13.6 \pm 1.52$ & $13.4 \pm 1.61$ & $13.2 \pm 1.59$ & $13.1 \pm 1.70$ \\
\hline $\mathrm{cS}(8.0 \mu \mathrm{g})$ & $25.4 \pm 3.08^{*}$ & $23.8 \pm 2.87^{*}$ & $24.1 \pm 2.89 *$ & $24.6 \pm 2.95^{*}$ \\
\hline
\end{tabular}

Measurements are expressed as means $\pm \operatorname{SEM}(n=8)$.

The groups were compared at the same time point.

$* p<0.01$, significant difference from the vehicle-treated animals.

Table 2. The inhibition of catalepsy by levodopa (L-DP).

\begin{tabular}{|l|c|c|c|c|}
\hline \multirow{2}{*}{ Drugs (dose) } & \multicolumn{4}{|c|}{$\begin{array}{c}\text { Duration of immobility (s) } \\
\text { at different time points after cS injection }\end{array}$} \\
\cline { 2 - 5 } & $\mathbf{6 0}$ min & $\mathbf{1 2 0}$ min & $\mathbf{1 8 0 ~ m i n}$ & $\mathbf{2 4 0}$ min \\
\hline Experiment II \\
\hline Vehoperated control & $9.4 \pm 1.12$ & $8.9 \pm 1.23$ & $9.9 \pm 1.28$ & $9.0 \pm 1.19$ \\
\hline cS & $11.3 \pm 1.32$ & $10.8 \pm 1.28$ & $10.1 \pm 1.17$ & $9.9 \pm 1.21$ \\
\hline cS + L-DP $(50 \mathrm{mg} / \mathrm{kg})$ & $27.1 \pm 3.04^{*}$ & $26.7 \pm 3.02^{*}$ & $25.9 \pm 2.94^{*}$ & $26.8 \pm 3.17^{*}$ \\
\hline$+\mathrm{L}-\mathrm{DP}(100 \mathrm{mg} / \mathrm{kg})$ & $14.8 \pm 1.92^{\dagger}$ & $16.4 \pm 2.36^{\dagger}$ & $15.7 \pm 2.08^{\dagger}$ & $15.8 \pm 2.19^{\dagger}$ \\
\hline$+\mathrm{L}-\mathrm{DP}(200 \mathrm{mg} / \mathrm{kg})$ & $10.2 \pm 1.26^{\dagger \dagger}$ & $9.6 \pm 1.08^{\dagger \dagger}$ & $10.7 \pm 1.27^{\dagger \dagger}$ & $9.9 \pm 1.31^{\dagger \dagger}$ \\
\hline
\end{tabular}

Measurements are expressed as means $\pm \operatorname{SEM}(n=8)$.

The groups were compared at the same time point.

${ }^{*} p<0.01$, significant difference from the vehicle-treated group.

${ }^{\dagger} p<0.05,{ }^{\dagger \dagger} p<0.01$, significant difference from the group treated with cS alone. 
Table 3. The inhibition of catalepsy by diphenhydramine (DPH), ranitidine, and thioperamide.

\begin{tabular}{|c|c|c|c|c|}
\hline \multirow[t]{2}{*}{ Drugs (dose) } & \multicolumn{4}{|c|}{$\begin{array}{l}\text { Duration of immobility (s) } \\
\text { at different time points after cS injection }\end{array}$} \\
\hline & $60 \mathrm{~min}$ & $120 \mathrm{~min}$ & $180 \mathrm{~min}$ & $240 \mathrm{~min}$ \\
\hline \multicolumn{5}{|c|}{ Experiment III } \\
\hline Unoperated control & $7.4 \pm 0.83$ & $7.7 \pm 0.89$ & $8.1 \pm 1.03$ & $7.8 \pm 0.86$ \\
\hline Vehicle & $8.9 \pm 1.06$ & $9.3 \pm 1.12$ & $9.4 \pm 1.17$ & $9.2 \pm 1.11$ \\
\hline $\mathrm{cS}$ & $25.7 \pm 3.08^{* *}$ & $27.4 \pm 3.19^{* *}$ & $26.9 \pm 2.97 * *$ & $27.0 \pm 3.24 * *$ \\
\hline $\mathrm{cS}+\mathrm{DPH}(5.0 \mu \mathrm{g})$ & $22.1 \pm 2.63$ & $20.8 \pm 2.41$ & $21.4 \pm 2.39$ & $20.7 \pm 2.33$ \\
\hline + DPH $(10.0 \mu \mathrm{g})$ & $16.9 \pm 1.93^{\dagger}$ & $17.7 \pm 1.99^{\dagger}$ & $17.5 \pm 2.12^{\dagger}$ & $17.4 \pm 2.11^{\dagger}$ \\
\hline + DPH $(20.0 \mu \mathrm{g})$ & $16.1 \pm 1.89^{\dagger}$ & $16.2 \pm 1.83^{\dagger}$ & $16.3 \pm 1.94^{\dagger}$ & $16.3 \pm 1.96^{\dagger}$ \\
\hline \multicolumn{5}{|c|}{ Experiment IV } \\
\hline Unoperated control & $10.3 \pm 1.13$ & $10.0 \pm 1.22$ & $9.8 \pm 1.18$ & $10.1 \pm 1.23$ \\
\hline Vehicle & $11.4 \pm 1.37$ & $11.8 \pm 1.30$ & $11.3 \pm 1.38$ & $11.5 \pm 1.32$ \\
\hline $\mathrm{cS}$ & $21.9 \pm 2.64^{*}$ & $22.5 \pm 2.49 *$ & $22.8 \pm 2.73 *$ & $22.4 \pm 2.58 *$ \\
\hline $\mathrm{cS}+\mathrm{DPH}(10.0 \mu \mathrm{g})$ & $13.7 \pm 1.64^{\dagger}$ & $14.1 \pm 1.68^{\dagger}$ & $14.4 \pm 1.73^{\dagger}$ & $14.2 \pm 1.76^{\dagger}$ \\
\hline+ ranitidine $(12.3 \mu \mathrm{g})$ & $19.4 \pm 2.33$ & $20.1 \pm 2.41$ & $19.8 \pm 2.38$ & $19.9 \pm 2.44$ \\
\hline+ thioperamide $(11.5 \mu \mathrm{g})$ & $22.3 \pm 2.67$ & $22.0 \pm 2.77$ & $22.6 \pm 2.71$ & $22.4 \pm 2.63$ \\
\hline
\end{tabular}

Measurements are expressed as means $\pm \operatorname{SEM}(n=8)$.

The groups were compared within the same experiment, at the same time point.

$* p<0.05, * * p<0.01$, significant difference from the vehicle-treated group.

${ }^{\dagger} p<0.05$, significant difference from the group treated with $\mathrm{cS}$ alone.

Table 4. The inhibition of catalepsy by nicotine (NCT).

\begin{tabular}{|c|c|c|c|c|}
\hline \multirow{2}{*}{ Drugs (dose) } & \multicolumn{4}{|c|}{$\begin{array}{c}\text { Duration of immobility (s) } \\
\text { at different time points after cS injection }\end{array}$} \\
\cline { 2 - 5 } & $\mathbf{6 0}$ min & $\mathbf{1 2 0}$ min & $\mathbf{1 8 0}$ min & $\mathbf{2 4 0}$ min \\
\hline \multicolumn{5}{|c|}{ Experiment V } \\
\hline Unoperated control & $10.1 \pm 1.23$ & $9.9 \pm 1.09$ & $9.6 \pm 1.1$ & $9.8 \pm 1.18$ \\
\hline Vehicle & $10.3 \pm 1.34$ & $9.8 \pm 1.14$ & $10.0 \pm 1.19$ & $9.7 \pm 1.06$ \\
\hline $\mathrm{cS}$ & $27.6 \pm 3.47^{*}$ & $27.2 \pm 3.53^{*}$ & $26.9 \pm 2.33^{*}$ & $27.4 \pm 2.8^{*}$ \\
\hline $\mathrm{cS}+\mathrm{NCT}(0.2 \mathrm{mg} / \mathrm{kg})$ & $22.3 \pm 2.68$ & $21.6 \pm 2.52$ & $21.9 \pm 2.71$ & $21.7 \pm 2.58$ \\
\hline$+\mathrm{NCT}(0.4 \mathrm{mg} / \mathrm{kg})$ & $18.0 \pm 2.29^{\dagger}$ & $17.7 \pm 2.39^{\dagger}$ & $17.3 \pm 2.05^{\dagger}$ & $17.4 \pm 2.33^{\dagger}$ \\
\hline$+\mathrm{NCT}(1.0 \mathrm{mg} / \mathrm{kg})$ & $17.1 \pm 2.09^{\dagger}$ & $16.9 \pm 2.08^{\dagger}$ & $17.2 \pm 2.24^{\dagger}$ & $16.8 \pm 2.11^{\dagger}$ \\
\hline
\end{tabular}

Measurements are expressed as means $\pm \operatorname{SEM}(n=8)$.

The groups were compared at the same time point.

${ }^{*} p<0.01$, significant difference from the vehicle-treated group.

${ }^{\dagger} p<0.05$, significant difference from the group treated with cS alone.

DPH-NCT combination. The effects of the drugs appeared to be nearly additive (Fig. 1, experiment VI), i.e., co-administration led to a significantly $(p<0.05)$ greater reduction in catalepsy than administration of each drug alone. These results suggest non-overlapping mechanisms behind the anti-cataleptic effects of diphenhydramine and nicotine. 


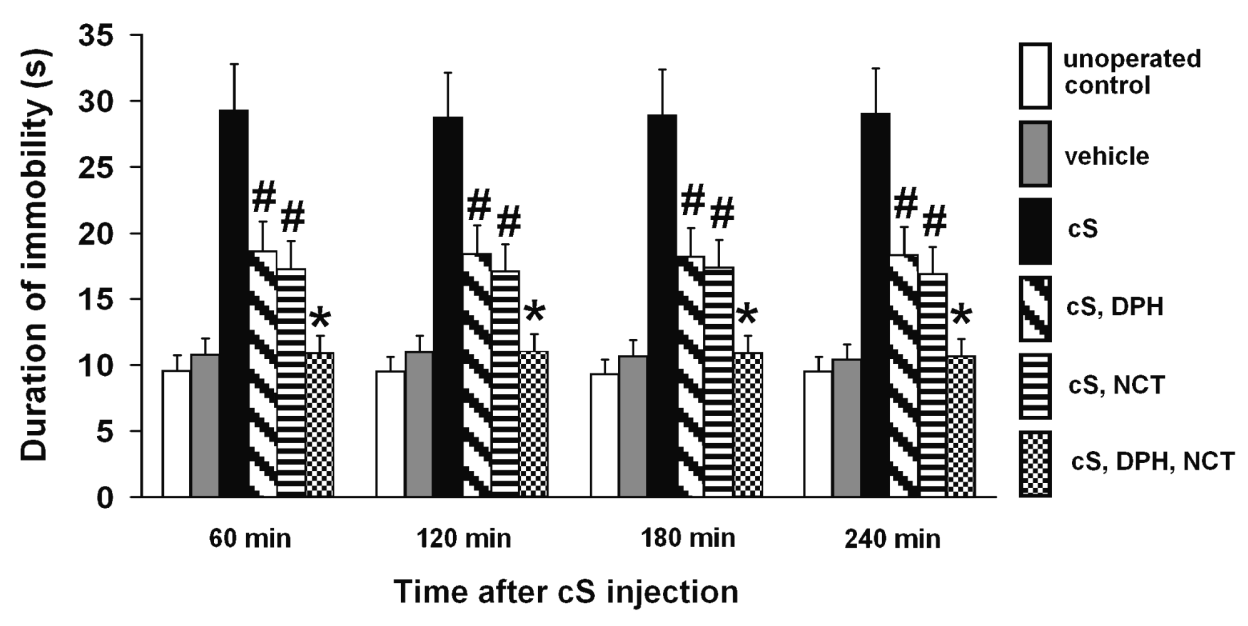

Fig. 1. Anticataleptic action of the diphenhydramine-nicotine combination (Experiment VI). The doses for DPH and NCT: $10 \mu \mathrm{g}$ and $0.4 \mathrm{mg} / \mathrm{kg}$, respectively. Measurements are expressed as means $\pm \mathrm{SEM}(\mathrm{n}=8)$. ${ }^{*} \mathrm{p}<0.05$, significant difference from vehicle-treated animals. ${ }^{*} p<0.05$, significant difference from animals given DPH or NCT alone.

\section{DISCUSSION}

In parkinsonian patients, a decrease in brain somatostatin levels takes place. To assess the pathogenic relevance of this abnormality, we recently studied the ability of a somatostatin antagonist, $\mathrm{cS}$, to induce catalepsy in rats. As was found, intracerebral injections of $\mathrm{cS}$ produce cataleptic response; the effect is observed in aged but not in young animals [8]. In the present study, the responsiveness of cS-induced catalepsy to some medications was examined. The results could be important from two standpoints. Sensitivity of the model to clinically effective medications would be evidence for the model's validity. At the same time, the results could provide approaches to the pharmacological management of the iPD as a state associated with central somatostatin deficiency.

As described above, levodopa (in combination with carbidopa) is able to antagonize cS-induced catalepsy (Table 2, experiment II). These data support a role for dopaminergic deficiency in cataleptogenic effect of cS. This role is hardly surprising. Catalepsy is frequently linked to an inhibition of the central dopaminergic activity [14, 15]. Somatostatin may well be a physiological regulator of brain dopaminergic systems. This factor is widely distributed across the rat brain (for refs., see [51]) and reportedly potentiates brain dopaminergic activity (for refs. see section 'Introduction'). Hence, it is quite expectable that somatostatin antagonist inhibits the dopaminergic neurotransmission and thus produces catalepsy. $\mathrm{Be}$ it as it may, cS-induced catalepsy was found to share with iPD features such as sensitivity to levodopa.

cS-induced catalepsy appeared to be sensitive to diphenhydramine, an $\mathrm{H}_{1}$-antagonist, whereas ranitidine and thioperamide at equimolar doses were ineffective (Table 3, experiment IV). Apparently, a stimulation of $\mathrm{H}_{1}$-receptors plays a role in the cataleptogenic effect of cS. Catalepsy induced by cS was only partly inhibited by diphenhydramine; the drug effect showed signs of plateauing in the range of large doses. In essence, the limited anticataleptic effect of diphenhydramine was similar to the effect of this drug in iPD. The use of diphenhydramine as an anti-parkinsonian agent was first tried in 1946, on a purely empirical basis, and a certain beneficial effect was observed [52]. This effect was later confirmed (e.g., [53, 54]).

A lower risk for iPD among tobacco smokers suggests the ability of nicotine to mitigate extrapyramidal disorders. Indeed, such an activity was observed here in the model of cS-induced catalepsy (Table 4, experiment V). The mechanism of anti-cataleptic activity of the drug in this model is obscure. Nicotine is reportedly able to increase the dopamine release from the nerve terminals (see section 'Introduction') which suggests its stimulatory action on dopaminergic neurotransmission. However, the 
functional significance for this nicotine-induced stimulation of dopaminergic processes is not obvious. Nicotine failed to attenuate catalepsy induced by a cataleptogen such as haloperidol [35-37] although cataleptic response to haloperidol is reversed by dopaminergic stimulants $[55,56]$. In light of these findings, the anti-cataleptic activity of nicotine seems to be cS-specific. It may well be that the anti-cataleptic effect of NCT in our experiments is linked to the ability of this drug to increase brain somatostatin concentrations [57].

Collectively, the available data show common features in cS-induced catalepsy and iPD. The model as well as human disease is associated with the same brain abnormality, a decrease in somatostatin activity. Both demonstrate a similar age-dependence [8]. In the present study, responsiveness of the model to clinically effective medications was found. These common features support the view that a fall in brain somatostatin levels can play a causative role in iPD; the similarity to the disease may characterize cS-induced catalepsy as a relatively valid model of iPD.

Given the possible pathogenic relevance of somatostatinergic deficiency in iPD, the results obtained in the cS-induced model can be of some prognostic value. In our experiments, diphenhydramine and nicotine displayed only limited anti-cataleptic activity (Tables 3 and 4, experiments III and V). A similar, not very strong, anti-parkinsonian effect, apparently is exerted by nicotine in tobacco smokers; the clinical effect of diphenhydramine described in the late 1940s was also moderate. Meanwhile, anti-cataleptic effects of diphenhydramine and nicotine in the present experiments appeared to be additive; in all likelihood, each drug exerted its effect independently. As was found here, the diphenhydramine-nicotine coadministration almost totally reversed catalepsy induced by $\mathrm{cS}$ (Fig. 1, experiment VI). These results suggest that combined treatment with diphenhydramine and nicotine is a feasible and promising approach for symptomatic treatment of extrapyramidal disorders.

\section{CONCLUSION}

It was shown here for the first time that cyclosomatostatin-induced catalepsy is responsive to clinically effective anti-parkinsonian agents levodopa, diphenhydramine, and nicotine. These findings support the pathogenic relevance of brain somatostatin in parkinsonism. Co-administration of diphenhydramine and nicotine reverses the cyclosomatostatin-induced catalepsy; this combination may be a new approach to the treatment of extrapyramidal disorders.

\section{ACKNOWLEDGMENTS}

I. D. I. is indebted to his long-standing mentors, Prof. Igor Efimovich Kovalev and Prof. Lev Aramovich Piruzyan. Technical support of this research by 'Timpharm LTD.' (Moscow, Russia) is highly appreciated.

\section{CONFLICT OF INTEREST STATEMENT}

The authors declare no competing interests.

\section{REFERENCES}

1. Hornykiewicz, O. 1998, Neurology, 51(2 Suppl. 2), S2.

2. Thomas, B. and Beal, M. F. 2007, Hum. Mol. Genet., 16(Spec. No. 2), R183.

3. Magrinelli, F., Picelli, A., Tocco, P., Federico, A., Roncari, L., Smania, N., Zanette, G. and Tamburin, S. 2016, Parkinsons Dis., doi: 10.1155/2016/9832839.

4. Reeve, A., Simcox, E. and Turnbull, D. 2014, Ageing Res. Rev., 14, 19.

5. Ascherio, A. and Schwarzschild, M. A. 2016, Lancet Neurol., 15, 1257.

6. Cotzias, G. C., Papavasiliou, P. S. and Gellene, R. 1969, N. Engl. J. Med., 280, 337.

7. Gubellini, P. and Kachidian, P. 2015, Rev. Neurol. (Paris), 171, 750.

8. Ionov, I. D. and Pushinskaya, I. I. 2013, Psychopharmacology, 227, 273.

9. Ionov, I. D. and Turgeneva, Z. A. 2015, Avicenna J. Neuro. Psycho. Physiol., 2, 16.

10. Chesselet, M. F. and Reisine, T. D. 1983, J. Neurosci., 3, 232.

11. Hathway, G. J., Emson, P. C., Humphrey, P. P. and Kendrick, K. M. 1998, J. Neurochem., 70, 1740 .

12. Hathway, G. J., Humphrey, P. P. and Kendrick, K. M. 2004, Neurosci. Lett., 358, 127.

13. Ionov, I. D., Pushinskaya, I. I., Roslavtseva, L. A. and Severtsev, N. N. 2018, Brain Res., 1691, 26. 
14. Fries, J. L., Murphy, W. A., Sueiras-Diaz, J. and Coy, D. H. 1982, Peptides, 3, 811.

15. Crocker, A. D. and Hemsley, K. M. 2001, Prog. Neuropsychopharmacol. Biol. Psychiatry, 25,573 .

16. Wadenberg, M. L., Soliman, A., VanderSpek, S. C. and Kapur, S. 2001, Neuropsychopharmacology, 25, 633.

17. Duty, S. and Jenner, P. 2011, Br. J. Pharmacol., 164, 1357.

18. Korner, G., Noain, D., Ying, M., Hole, M., Flydal, M. I., Scherer, T., Allegri, G., Rassi, A., Fingerhut, R., Becu-Villalobos, D., Pillai, S., Wueest, S., Konrad, D., Lauber-Biason, A., Baumann, C. R., Bindoff, L. A., Martinez, A. and Thöny, B. 2015, Brain, 138, 2948.

19. Schwartz, J. C., Arrang, J. M., Garbarg, M., Pollard, H. and Ruat, M. 1991, Physiol. Rev., 71,1 .

20. Krusong, K., Ercan-Sencicek, A. G., Xu, M., Ohtsu, H., Anderson, G. M., State, M. W. and Pittenger, C. 2011, Neurosci. Lett., 495, 110.

21. Maisonnette, S., Huston, J. P., Brandao, M. and Schwarting, R. K. 1998, Exp. Brain Res., 120, 273.

22. Itoh, Y., Nishibori, M., Oishi, R. and Saeki, K. 1984, Neurosci. Lett., 48, 305.

23. Jain, N. S., Tandi, L. and Verma, L. 2015, Pharmacol. Biochem. Behav., 139, 59.

24. Vizuete, M. L., Merino, M., Venero, J. L., Santiago, M., Cano, J. and Machado, A. 2000, J. Neurochem., 75, 540.

25. Kamei, C., Dabasaki, T. and Tasaka, K. 1983, Jpn. J. Pharmacol., 33, 1081.

26. Onodera, K. and Shinoda, H. 1991, Agents Actions, 33, 143.

27. Ionov, I. D. and Severtsev, N. N. 2012, Psychopharmacology (Berl.), 223, 191.

28. Dringenberg, H. C., de Souza-Silva, M. A., Schwarting, R. K. and Huston, J. P. 1998, Naunyn Schmiedebergs Arch. Pharmacol., 358, 423.

29. Malec, D. and Langwiński, R. 1983, Pol. J. Pharmacol. Pharm., 35, 293.

30. Quik, M., O'Leary, K. and Tanner, C. M. 2008, Mov. Disord., 23, 1641.

31. Behmand, R. A. and Harik, S. I. 1992, J. Neurochem., 58, 776.
32. Giorguieff-Chesselet, M. F., Kemel, M. L., Wandscheer, D. and Glowinski, J. 1979, Life Sci., 25, 1257.

33. Teng, L., Crooks, P. A., Sonsalla, P. K. and Dwoskin, L. P. 1997, J. Pharmacol. Exp. Ther., 280, 1432.

34. Lecca, D., Shim, I., Costa, E. and Javaid, J. I. 2000, Neuropharmacology, 39, 88.

35. Emerich, D. F., Norman, A. B. and Sanberg, P. R. 1991, Psychopharmacol. Bull., 27, 385.

36. Sanberg, P. R., Emerich, D. F., el-Etri, M. M., Shipley, M. T., Zanol, M. D., Cahill, D. W. and Norman, A. B. 1993, Pharmacol. Biochem. Behav., 46, 303.

37. Boye, S. M. and Clarke, P. B. 2000, Can. J. Physiol. Pharmacol., 78, 882.

38. Zarrindast, M. R., Haeri-Zadeh, F., Zarghi, A. and Lahiji, P. 1998, J. Psychopharmacol., $12,279$.

39. Zarrindast, M. R., Samadi, P., Haeri-Rohani, A., Moazami, N. and Shafizadeh, M. 2002, Pharmacol. Biochem. Behav., 72, 197.

40. Ooka, H., Fujita, S. and Yoshimoto, E. 1983, Mech. Ageing Dev., 22, 113.

41. Klein, M. C. and Gertner, S. B. 1983, Neuropharmacology, 22, 1109.

42. Dyr, W., Koros, E., Bienkowski, P. and Kostowski, W. 1999, Alcohol Alcohol., 34, 43.

43. Onzawa, Y., Kimura, Y., Uzuhashi, K., Shirasuna, M., Hirosawa, T., Taogoshi, T. and Kihira, K. 2012, Biol. Pharm. Bull., 35, 1244.

44. de Carvalho, C. R., Hoeller, A. A., Franco, P. L., Martini, A. P., Soares, F. M., Lin, K., Prediger, R. D., Whalley, B. J. and Walz, R. 2016, Epilepsy Res., 127, 160.

45. Antunes-Rodrigues, J. and McCann, S. M. 1970, Proc. Soc. Exp. Biol. Med., 133, 1464.

46. Crofton, J. T., Rockhold, R. W., Share, L., Wang, B. C., Horovitz, Z. P., Manning, M. and Sawyer W. H. 1981, Hypertension, 3 (6 Pt 2), II-71.

47. Erzin-Waters, C., Muller, P. and Seeman, P. 1976, Can. J. Physiol. Pharmacol., 54, 516.

48. Sanberg, P. R., Pisa, M. and Fibiger, H. C. 1981, Eur. J. Pharmacol., 74, 347.

49. Dijk, S., Krugers, H. J. and Korf, J. 1991, Neuropharmacology, 30, 469.

50. Kheradmand, A., Nayebi, A. M., Jorjani, M. and Haddadi, R. 2016, Iran J. Basic Med. Sci., 19, 490. 
51. Stengel, A., Karasawa, H. and Taché, Y. 2015, Horm. Behav., 73, 15.

52. Budnitz, J. 1948, N. Engl. J. Med., 238, 874.

53. Ryan, G. M. and Wood, J. S. 1949, Lancet, 1(6546), 258.

54. Effron, A. S. and Denker, P. G. 1950, J. Am. Med. Assoc., 144, 5.
55. Svensson, K., Eriksson, E. and Carlsson, A. 1993, Neuropharmacology, 32, 1037.

56. Maj, J., Rogóz, Z., Skuza, G. and Kołodziejczyk, K. 1997, Eur. J. Pharmacol., 324, 31.

57. Barrios, V., González-Parra, S. and Arilla, E. 1992, Life Sci., 51, 1991. 